\title{
Recruitment of Dental Hygiene Students from Underrepresented Minority Groups: A National Survey of U.S. Dental Hygiene Programs
}

\author{
Jennifer M. Hunter, DDS; Janet S. Kinney, RDH, MS; Marita R. Inglehart, Dr phil habil
}

Abstract: The aims of this study were to assess how U.S. undergraduate dental hygiene programs recruit students, especially students from underrepresented minority (URM) groups, and how the program directors value recruiting those students, how satisfied they are with their efforts, which practices they use, and which challenges they encounter. Relationships between diversityrelated recruitment motivation and satisfaction and the program and recruitment characteristics were also explored. Survey data were collected from 56 of the 287 programs that could be successfully contacted with individual emails to their directors (response rate: $20 \%)$. The majority of responding programs recruited students into their programs by using written materials (91\%), websites $(91 \%)$, on-campus events (77\%), and high school visits (52\%). However, only $20 \%$ had written materials and $13 \%$ special events for recruiting students from URM groups. While $75 \%$ of the responding program directors considered high grade point averages (GPAs) to be a priority and 85\% thought high GPAs were important/very important when recruiting students, only $17 \%$ considered it a priority to recruit URM students, and only $35 \%$ reported thinking it was important/very important to do so. The more of a priority it was to have a diverse student body and the more important the respondents considered it, the more likely they were to have written URM-specific recruitment materials $(\mathrm{r}=0.34 ; \mathrm{p}<0.05 / \mathrm{r}=0.39 ; \mathrm{p}<0.01)$. The more the respondents valued ACT scores, the less likely they were to engage in URM-specific recruitment efforts $(r=-0.38 ; p<0.05 / r=-0.34 ; p<0.05)$. If the dental hygiene profession is to better reflect the racial/ethnic makeup of the U.S. population, dental hygiene programs' considerations and efforts related to the recruitment of URM students need to be reconsidered.

Dr. Hunter is a first-year GPR resident, Bronx Lebanon Hospital Center; Prof. Kinney is Clinical Associate Professor, Research Scientist, and Director of Dental Hygiene Program, Department of Periodontics and Oral Medicine, School of Dentistry, University of Michigan; and Dr. Inglehart is Professor, Department of Periodontics and Oral Medicine, School of Dentistry and Adjunct Professor, Department of Psychology, College of Literature, Science, and Arts, University of Michigan. Direct correspondence to Dr. Marita R. Inglehart, Department of Periodontics and Oral Medicine, University of Michigan School of Dentistry, 1011 North University Avenue, Ann Arbor, MI 48109-1078; 734-763-8073; mri@umich.edu.

Keywords: dental hygiene, dental hygiene education, allied dental education, access to health care, minority groups, minority health, cultural diversity, underrepresented minority students

Submitted for publication 4/6/15; accepted 4/22/15

$\mathrm{I}$ n 2000, the first U.S. surgeon general's report on oral health drew attention to the fact that certain segments of the population suffer from disproportionate amounts of oral disease and face problems when trying to access oral health care services. ${ }^{1}$ Patients from underrepresented minority (URM) groups were especially vulnerable to these problems. Increasing the numbers of dental care providers from URM groups is one way to increase access to care for these patients because URM health care professionals have provided significantly more services for poor and minority patients than non-minority providers. ${ }^{2-11}$ However, a decade ago, the Sullivan report, Missing Persons: Minorities in the Health Professions, noted that individuals from URM groups were clearly underrepresented among both students in health professions schools and health care providers. ${ }^{5}$

In U.S. dental hygiene programs, the underrepresentation of URM students has been well documented over the past decades. Dhir et al. found in their 1998 survey of dental hygiene programs that only $10.5 \%$ of students were members of ethnic/racial minorities. ${ }^{12}$ When Woolfolk and Price provided an overview of the percentages of black, Hispanic, American Indian, Asian, and white dental hygiene students for academic years 2000-01 to 2009-10, they 
reported that the percentage of black students ranged from $3.7 \%$ to $4.4 \%$ in that ten-year period and the percentage of Hispanic students from 5.7\% to $7.7 \% .^{13}$ The American Dental Association (ADA) 2010-11 Survey of Allied Dental Education found that only $13.7 \%$ of enrolled dental hygiene students were from underrepresented racial and ethnic groups, although these groups represented $29.8 \%$ of the U.S. population. ${ }^{14}$ This underrepresentation of dental hygiene students is paralleled by small numbers of dental hygiene faculty members from URM groups. ${ }^{14,15} \mathrm{In}$ 2004, Nunn et al. reported that $92 \%$ of the dental hygiene faculty at the 188 programs they surveyed were white. ${ }^{15}$ Given these statistics concerning dental hygiene students and faculty members, it is not surprising that members of URM groups are also clearly underrepresented among practicing dental hygienists, ${ }^{4}$ which results in a lack of role models for potential URM students. ${ }^{16}$

Dental schools have made major efforts over the past decades to increase the number of dental students from URM groups. ${ }^{2,17-19}$ The Commission on Dental Accreditation (CODA) standards for dental schools even require these schools to take steps to make their environments more diverse..$^{20}$ However, no research so far has explored whether dental hygiene programs also engage in specific diversityrelated recruitment efforts. While CODA standards for dental hygiene programs do not require these programs to have a diverse community of students, staff, and faculty members, ${ }^{21}$ there are significant educational benefits for dental hygiene programs when they have increased numbers of URM students. ${ }^{10}$ For example, research has shown that being educated in a diverse setting increased students' cultural competence-which ultimately results in more culturally sensitive patient care. . $^{72,22,23}$

In consideration of the low percentages of URM students in U.S. dental hygiene programs, one central question of interest concerns what efforts these programs make concerning the recruitment of URM students. The aims of this study therefore were to assess how U.S. dental hygiene programs recruit students, especially students from URM groups, and how these program directors value recruiting students from URM groups, how satisfied they are with their efforts, which practices they use, and which challenges they encounter. In addition, the relationships between diversity-related recruitment motivation and satisfaction and program and recruitment characteristics were explored.

\section{Methods}

This study was determined to be exempt from Institutional Review Board oversight by the Institutional Review Board for the Behavioral and Health Sciences at the University of Michigan (HUM\#00088723) on May 5, 2014. An a priori power analysis was conducted with the G3.1.3 Power Analysis Program (www.psycho.uni-duesseldorf.de/ abteilungen/aap/gpower3/). Given that correlations between the priority-, importance-, and satisfactionrelated responses and the program- and recruitmentrelated characteristics were of interest, the a priori power analysis was used to determine the needed number of subjects when using a t-test to test for the significance of a correlation with a two-sided hypothesis, an alpha error probability of 0.05 , a relatively medium to large effect size of $|\rho|=0.40$, and a power of 0.80 . The results showed that a sample size of 44 respondents was required.

A survey was developed and pilot tested with ten dental hygienists in the state of Michigan. After receiving feedback from these pilot subjects, a final version of the survey was developed. Individual personalized recruitment emails were then sent to the directors of all 335 undergraduate dental hygiene programs in the United States. Of these, 48 emails could not be delivered, resulting in 287 successfully contacted programs. Program directors responded to the recruitment email by connecting through the web link provided to a web-based anonymous survey. No follow-up emails were sent because it was unclear which programs had responded to the original emails.

The survey consisted of four parts. Part 1 asked for information about program and student characteristics, and Part 2 contained questions concerning the programs' recruitment efforts in general and their specific efforts related to recruiting URM students. Part 3 asked seven questions concerning to what degree it is a priority for the program directors to recruit undergraduate dental hygiene students with various characteristics such as high $\mathrm{ACT} / \mathrm{SAT}$ scores, high grade point averages, professional experiences, family background in the health care field, high involvement with community service, and being from diverse backgrounds and underrepresented minority groups. In addition, this third part asked 15 questions concerning how important and how satisfied the program directors were with recruiting students with these same seven characteristics as well as eight other diversity-related characteristics. All answers to 
the priority, importance, and satisfaction questions were given on a five-point scale, with 1 as the lowest response and 5 as the highest.

Part 4 of the survey consisted of four openended questions that asked respondents to describe the biggest challenges they encountered and the most effective practices they used when recruiting students in general and students from URM groups specifically into their programs. These questions were as follows: "Which are your biggest challenges concerning recruiting students into your program in general?"; "Which are your biggest challenges concerning recruiting diverse students, such as from underrepresented minority groups or from socioeconomically disadvantaged backgrounds, into your program?"; "Which practices for recruiting students into your program in general do you find most effective?"; and "Which practices for recruiting students from diverse groups or backgrounds do you find most effective?"

The data were downloaded from the website as an Excel file and imported into SPSS (Version 22). Descriptive statistics such as frequency distributions, percentages, means, and standard deviations were computed to provide an overview of the responses. Inferential statistics were used to test whether relationships between variables were significant. The answers to the open-ended questions in Part 4 were transcribed and independently coded by two of the three authors. Any discrepancies were discussed and resolved. A $p<0.05$ was accepted as the level of significance.

\section{Results}

Data were collected from 56 of the 287 dental hygiene programs that could be successfully contacted with individual emails to their program directors (response rate: $20 \%$ ). Table 1 provides an overview of the respondents' program and student characteristics. Most programs were part of a community or junior college (54\%), a university or four-year college $(20 \%)$, or a dental school (11\%). Of these programs, $75 \%$ granted an associate degree, $29 \%$ a baccalaureate degree, $11 \%$ a master's degree, and $5 \%$ a diploma/ certificate (respondents could select all that applied). While all programs were undergraduate dental hygiene programs, $31 \%$ also had a degree completion program and $11 \%$ a graduate program. However, it was made very clear in the survey instructions that only recruitment efforts related to the undergraduate program were to be considered in the directors' responses. The lengths of the programs ranged from 13 to 40 months, with an average of 22 months.

The number of applicants to these programs ranged from five to 450 in a typical year. The num-

\begin{tabular}{|c|c|c|c|c|c|}
\hline Program Characteristic & Number & Percentage & Student Characteristic & Mean & SD (Range) \\
\hline \multicolumn{3}{|l|}{ Educational setting } & \multirow{3}{*}{$\begin{array}{l}\text { Number of applicants for } \\
\text { undergraduate program in a } \\
\text { typical year }\end{array}$} & \multirow[t]{3}{*}{97} & \multirow{3}{*}{$\begin{array}{l}76.08 \\
(5-450)\end{array}$} \\
\hline School of allied health sciences & 2 & $4 \%$ & & & \\
\hline Dental school & 6 & $11 \%$ & & & \\
\hline Separate dental department & 0 & 0 & \multirow{4}{*}{$\begin{array}{l}\text { Number of graduates from } \\
\text { undergraduate program in a } \\
\text { typical year }\end{array}$} & \multirow[t]{5}{*}{23} & \multirow{5}{*}{$\begin{array}{c}9.20 \\
(10-48)\end{array}$} \\
\hline University or four-year college & 11 & $20 \%$ & & & \\
\hline Community or junior college & 30 & $54 \%$ & & & \\
\hline Technical college & 4 & $7 \%$ & & & \\
\hline Other & 1 & $2 \%$ & $\begin{array}{l}\text { Number of students in undergraduate } \\
\text { class by characteristic }\end{array}$ & & \\
\hline \multicolumn{3}{|l|}{ Type of degree ${ }^{+}$} & \multirow[t]{2}{*}{ Male } & \multirow[t]{2}{*}{1} & \multirow{2}{*}{$\begin{array}{l}0.89 \\
(0-4)\end{array}$} \\
\hline Diploma/certificate & 3 & $5 \%$ & & & \\
\hline Associate degree & 42 & $75 \%$ & \multirow{2}{*}{$\begin{array}{l}\text { Socioeconomically } \\
\text { disadvantaged }\end{array}$} & \multirow[t]{2}{*}{7} & \multirow{2}{*}{$\begin{array}{l}7.49 \\
(0-30)\end{array}$} \\
\hline Baccalaureate degree & 16 & $29 \%$ & & & \\
\hline Master's degree & 6 & $11 \%$ & African American & 1 & $\begin{array}{l}1.97 \\
(0-12)\end{array}$ \\
\hline \multicolumn{2}{|l|}{ Type of program ${ }^{+}$} & $100 \%$ & American Indian & 0 & $\begin{array}{l}0.73 \\
(0-4)\end{array}$ \\
\hline $\begin{array}{l}\text { Graduate } \\
\text { Degree completion }\end{array}$ & $\begin{array}{c}6 \\
17\end{array}$ & $\begin{array}{l}11 \% \\
31 \%\end{array}$ & Asian American & 2 & $\begin{array}{l}2.77 \\
(0-18)\end{array}$ \\
\hline Length of program in months & $\begin{array}{l}\text { Mean= } \\
22.36\end{array}$ & $\begin{array}{c}\mathrm{D}= \\
5.24 \\
\mathrm{~S}(13-40)\end{array}$ & Hispanic/Latina/o & 3 & $\begin{array}{l}2.44 \\
(0-10)\end{array}$ \\
\hline
\end{tabular}

${ }^{\dagger}$ Respondents could choose all that applied. 
ber of graduates ranged from ten to 48 in a typical year, with an average number of 23. Of these 23 graduates, seven students on average were from a socioeconomically disadvantaged background, three were Hispanic/Latina/o, two were Asian American, one was African American, and none were American Indian.

The responses concerning recruitment efforts showed that $43 \%$ of the responding programs had a designated recruiter of students (Table 2). As the recruiter, $25 \%$ of the programs had a dental hygienist,
$9 \%$ an admissions program staff member, $5 \%$ recruitment staff, and only one program had a dentist and a psychologist recruit students. Additional persons who supported recruitment efforts were faculty members (reported by $41 \%$ of the programs), program administrators $(20 \%)$, students (18\%), high school advisors (14\%), and recruitment staff members from outside of their unit $(5 \%)$.

When asked how they recruited students into their programs, $91 \%$ of the respondents indicated they had written materials and websites, while $25 \%$

Table 2. Participants' responses concerning student recruitment efforts $(\mathrm{N}=56)$

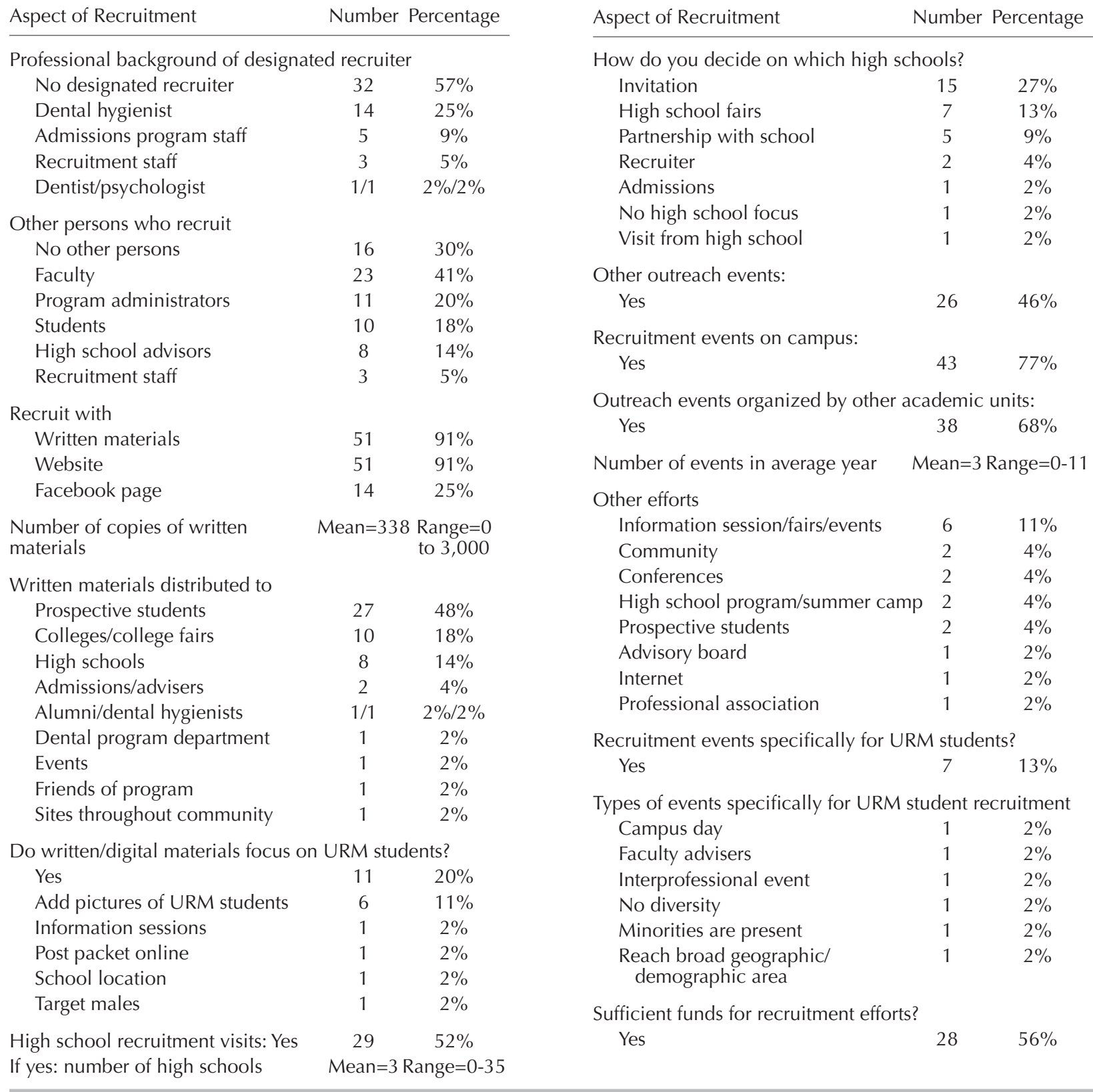


had a Facebook page. The numbers of printed copies of the written materials ranged extremely widely, from some programs not having any written materials to one program printing 3,000 copies of written materials. On average, 338 copies were printed of written recruitment materials. Written materials were most likely to be distributed to prospective students (reported by $48 \%$ of the programs), at college visits or college fairs $(18 \%)$, and in high schools $(14 \%)$. When asked if their programs had written materials that focused on URM students, 11 program directors reported having such materials. In response to a follow-up question inquiring how they designed URM-specific written material, six of the 11 program directors reported having added pictures of URM students.

Among the responding programs, $52 \%$ reported making high school recruitment visits. Most of these high school visits were by invitation from the schools $(27 \%)$ or to high school fairs (13\%). Although only $9 \%$ had a partnership with a specific high school, $46 \%$ had other additional outreach efforts, $77 \%$ participated in recruitment events in the school and on their own campus, and $68 \%$ were present at events organized by other academic units. The number of recruitment events in an average year ranged from zero to 11, with an average of three. Two programs described that they had a high school program/ summer camp, met prospective students at information sessions, fairs, and other events, and used the Internet for recruitment efforts. Only seven schools reported having specific recruitment events for URM students (13\%); specific efforts at these URM student recruitment events were to have minorities present, to have faculty advisors there, and to participate in interprofessional events. Among the total respondents, $56 \%$ indicated that they had sufficient funds for recruitment.

When asked how much of a priority it is for their program to recruit undergraduate dental hygiene students with various characteristics, $75 \%$ of the respondents indicated that high GPAs were the high or highest priority and 37\% that high ACT/SAT scores were the high or highest priority for them (Table 3). Regarding diversity, 19\% of the respondents considered it a high or highest priority to have students from diverse backgrounds in their programs and $17 \%$ to have students from URM groups among their students.

Table 4 provides an overview about how important the program directors thought certain student characteristics would be during the recruitment process and how satisfied they were with recruiting students with those characteristics. Concerning the importance ratings, high GPAs were of great importance for $85 \%$ of the program directors. On the other hand, having a family background in the health professions was considered least important, with $89 \%$ of the respondents indicating that this characteristic was not at all/not very important. Concerning diversity-related responses, $35 \%$ of the respondents considered it as important/very important to recruit students from URM groups, $32 \%$ to recruit African American students, and 29\% to recruit Hispanic/ Latina/o students.

The satisfaction ratings showed that $78 \%$ of the responding program directors were satisfied/very satisfied with how they recruited students with high GPAs into their programs. On average, the program directors had neutral to positive satisfaction ratings

Table 3. Dental hygiene program directors' priority ratings of applicant characteristics, by percentage of total respondents to each item $(\mathrm{N}=56)$

\begin{tabular}{|c|c|c|c|c|c|c|}
\hline Priority Characteristic & 1 & 2 & 3 & 4 & 5 & Mean (SD) \\
\hline High ACT/SAT scores & $46 \%$ & $11 \%$ & $7 \%$ & $32 \%$ & $5 \%$ & $2.39(1.45)$ \\
\hline High grade point averages & $14 \%$ & $2 \%$ & $9 \%$ & $34 \%$ & $41 \%$ & $3.86(1.36)$ \\
\hline Professional experiences in dental office & $28 \%$ & $26 \%$ & $28 \%$ & $12 \%$ & $7 \%$ & $2.44(1.22)$ \\
\hline Family background in the health professions & $75 \%$ & $21 \%$ & $2 \%$ & $2 \%$ & $0 \%$ & $1.32(0.64)$ \\
\hline High involvement with community service ${ }^{\dagger}$ & $32 \%$ & $16 \%$ & $25 \%$ & $21 \%$ & $7 \%$ & $2.55(1.32)$ \\
\hline Diverse backgrounds ${ }^{\dagger}$ & $32 \%$ & $18 \%$ & $32 \%$ & $14 \%$ & $5 \%$ & $2.41(1.21)$ \\
\hline Underrepresented minority groups ${ }^{\dagger}$ & $33 \%$ & $19 \%$ & $33 \%$ & $12 \%$ & $5 \%$ & $2.37(1.20)$ \\
\hline Average diversity-related priorities ${ }^{\ddagger}$ & & & & & & $2.47(1.09)$ \\
\hline
\end{tabular}
(alpha $=0.851)$

Note: Survey item was worded: "It is a priority to recruit undergraduate dental hygiene students with/from" followed by the list of characteristics. Responses ranged from $1=$ no priority at all to $5=$ highest priority. Percentages may not total $100 \%$ due to rounding. ${ }^{\dagger}$ Diversity-related question

未The average diversity-related priority score was computed by averaging the responses to the three diversity-related questions. 
Table 4. Dental hygiene program directors' perceived importance of and satisfaction with students' characteristics in recruitment process, by percentage of total respondents to each item $(\mathrm{N}=56)$

\begin{tabular}{|c|c|c|c|c|c|c|c|c|}
\hline \multirow[b]{2}{*}{ Students' Characteristic } & \multicolumn{4}{|c|}{ Importance Rating } & \multicolumn{4}{|c|}{ Satisfaction Rating } \\
\hline & $1 / 2$ & 3 & $4 / 5$ & Mean & $1 / 2$ & 3 & $4 / 5$ & Mean \\
\hline High ACT/SAT scores & $40 \% / 9 \%$ & $13 \%$ & $21 \% / 17 \%$ & 2.66 & $10 \% / 4 \%$ & $18 \%$ & $39 \% / 29 \%$ & 3.71 \\
\hline High grade point averages & $2 \% / 4 \%$ & $9 \%$ & $36 \% / 49 \%$ & 4.26 & $2 \% / 6 \%$ & $14 \%$ & $47 \% / 31 \%$ & 4.00 \\
\hline Professional experiences in dental offices & $25 \% / 28 \%$ & $32 \%$ & $11 \% / 4 \%$ & 2.42 & $2 \% / 4 \%$ & $33 \%$ & $31 \% / 29 \%$ & 3.82 \\
\hline Family background in the health professions & $66 \% / 23 \%$ & $8 \%$ & $4 \% / 0$ & 1.49 & $6 \% / 4 \%$ & $36 \%$ & $26 \% / 28 \%$ & 3.66 \\
\hline High involvement with community service ${ }^{+}$ & $19 \% / 15 \%$ & $23 \%$ & $34 \% / 9 \%$ & 3.00 & $2 \% / 8 \%$ & $33 \%$ & $31 \% / 26 \%$ & 3.71 \\
\hline Diverse backgroundst & $21 \% / 6 \%$ & $39 \%$ & $27 \% / 8 \%$ & 2.94 & $2 \% / 20 \%$ & $28 \%$ & $28 \% / 24 \%$ & 3.51 \\
\hline Underrepresented minority groups ${ }^{+}$ & $19 \% / 10 \%$ & $37 \%$ & $25 \% / 10 \%$ & 2.96 & $4 \% / 26 \%$ & $24 \%$ & $24 \% / 24 \%$ & 3.37 \\
\hline Male students ${ }^{\dagger}$ & $17 \% / 6 \%$ & $47 \%$ & $21 \% / 9 \%$ & 3.00 & $4 \% / 28 \%$ & $26 \%$ & $22 \% / 22 \%$ & 3.29 \\
\hline Socioeconomically disadvantaged students ${ }^{\dagger}$ & $17 \% / 6 \%$ & $49 \%$ & $25 \% / 4 \%$ & 2.92 & $6 \% / 22 \%$ & $31 \%$ & $16 \% / 26 \%$ & 3.33 \\
\hline African American students ${ }^{\dagger}$ & $19 \% / 11 \%$ & $38 \%$ & $26 \% / 6 \%$ & 2.89 & $4 \% / 24 \%$ & $33 \%$ & $18 \% / 22 \%$ & 3.29 \\
\hline American Indian students ${ }^{\dagger}$ & $21 \% / 14 \%$ & $35 \%$ & $25 \% / 6 \%$ & 2.81 & $8 \% / 22 \%$ & $33 \%$ & $20 \% / 18 \%$ & 3.18 \\
\hline Asian American students ${ }^{\dagger}$ & $21 \% / 10 \%$ & $39 \%$ & $25 \% / 6 \%$ & 2.85 & $4 \% / 20 \%$ & $29 \%$ & $20 \% / 28 \%$ & 3.47 \\
\hline European American students ${ }^{\dagger}$ & $25 \% / 8 \%$ & $42 \%$ & $21 \% / 6 \%$ & 2.75 & $2 \% / 12 \%$ & $33 \%$ & $27 \% / 27 \%$ & 3.63 \\
\hline Hispanic/Latina/o students ${ }^{\dagger}$ & $19 \% / 12 \%$ & $40 \%$ & $23 \% / 6 \%$ & 2.85 & $4 \% / 16 \%$ & $35 \%$ & $20 \% / 26 \%$ & 3.47 \\
\hline International students ${ }^{\dagger}$ & $31 \% / 21 \%$ & $31 \%$ & $14 \% / 4 \%$ & 2.38 & $6 \% / 10 \%$ & $44 \%$ & $13 \% / 27 \%$ & 3.44 \\
\hline $\begin{array}{l}\text { Diversity-related index }{ }^{\ddagger} \\
\quad(\text { alpha }=0.974 / \text { alpha }=0.968)\end{array}$ & & & & 2.91 & & & & 3.53 \\
\hline
\end{tabular}

Note: Survey item was worded: "How important is it to recruit/How satisfied are you with recruiting students with/from" followed by the list of characteristics. Responses ranged from $1=$ not at all to $5=$ very. Percentages may not total $100 \%$ due to rounding.

'Diversity-related question

₹The diversity-related importance index was computed by averaging the responses to the single importance items. The diversity-related satisfaction index was computed by averaging the responses to the single satisfaction items.

concerning their efforts to recruit students from diverse backgrounds or groups. The lowest average satisfaction was with the recruitment of American Indian students.

In addition to the closed-ended questions, open-ended questions inquired what the programs' biggest challenges were when recruiting students in general and specifically when recruiting URM students. Time, cost, and a lack of qualified students were the three most frequently named challenges, both when recruiting students in general and when recruiting students from URM groups (Table 5). A lack of jobs, a lack of funds, the program's location, and a lack of student interest were cited as other challenges. Four of the programs indicated that they had no active recruitment of students from diverse groups or backgrounds.

When asked about their most effective practices when recruiting in general, word of mouth advertising was reported by seven programs, followed by having staff available to answer questions and inquiries from interested students, attending career fairs, and talking one-on-one with students (Table 5). Concerning most effective practices for recruiting students from URM groups, two programs reported word of mouth, two attending career fairs and talk- ing one-on-one, and two having special information sessions. The reputation of the program was also mentioned twice.

Table 6 provides an overview of the relationships between the program directors' priorities, their importance and satisfaction ratings, and their program characteristics such as number of applicants overall, number of graduates in an average year, and program length in months. The results showed that having ACT scores as a priority was positively correlated with number of applicants $(r=0.41 ; p<0.01)$. Higher numbers of applicants were also positively correlated with higher importance ratings of ACT/ SAT scores $(r=0.29 ; \mathrm{p}<0.05)$ and GPAs $(r=0.27$; $\mathrm{p}<0.05$ ). However, the number of graduates in an average year and the length of the program did not correlate with any of the priority, importance, or satisfaction ratings. While the percentages of URM students among the graduates in an average year were not correlated with priority and importance ratings, they were correlated with the satisfaction index concerning having URM students among their graduates. Concerning the relationships between special efforts to recruit URM students and the program directors' priority, importance, and satisfaction ratings, the more the respondents made it a priority to have a 
Table 5. Open-ended question responses from dental hygiene program directors concerning challenges and most effective practices when recruiting students in general and URM students, by number in each category $(\mathrm{N}=56)$

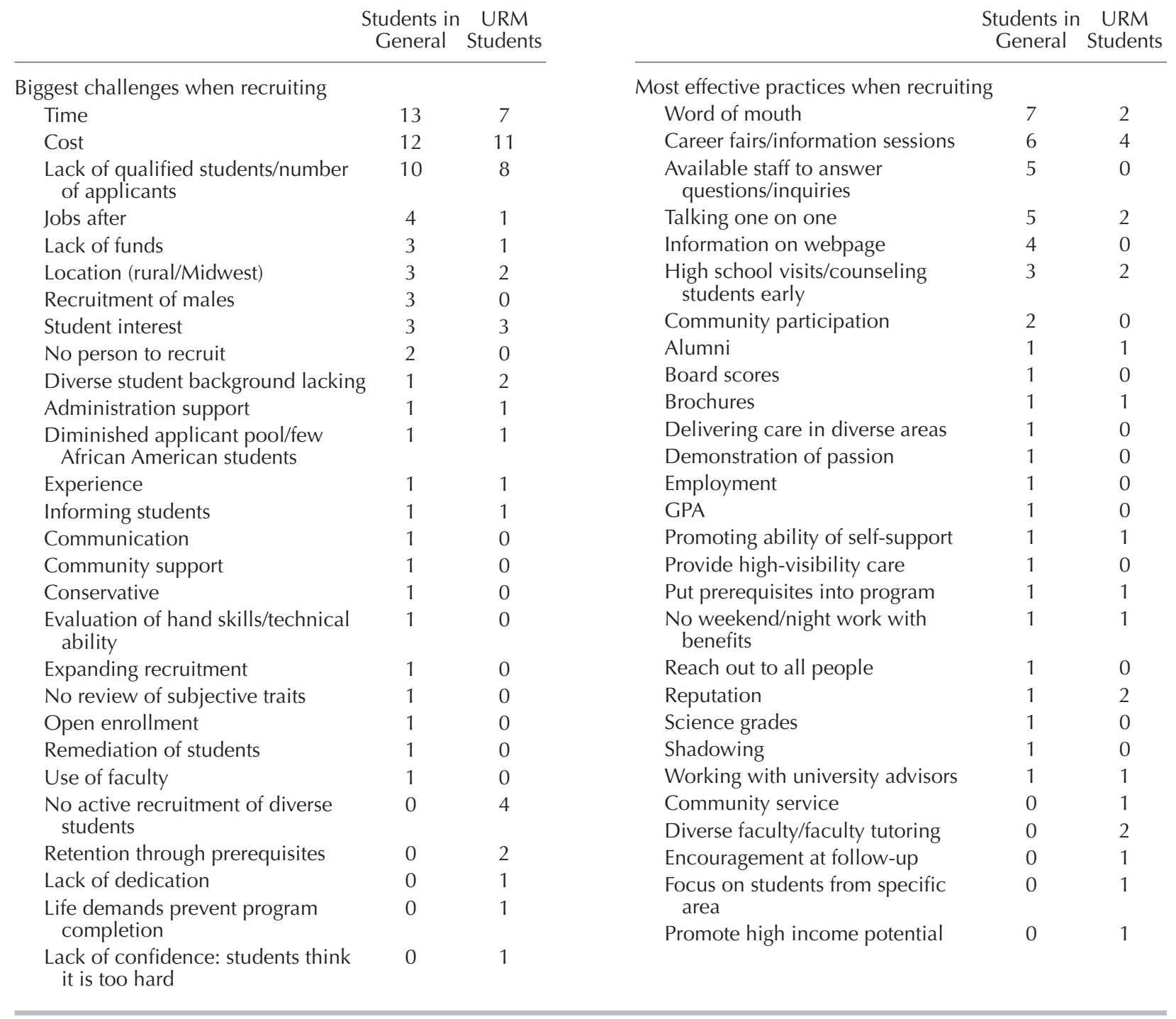

diverse student body and the more important it was for them, the more written material they used $(\mathrm{r}=0.34$; $\mathrm{p}<0.05 / \mathrm{r}=0.39 ; \mathrm{p}<0.01)$. However, the higher their importance ratings of ACT scores, the less likely they were to have special events for recruiting URM students $(\mathrm{r}=-0.34 ; \mathrm{p}<0.05)$.

\section{Discussion}

The findings from this survey concerning the low numbers of URM students in the responding dental hygiene programs were consistent with the data reported in previous studies. ${ }^{12-14}$ Gaining a better understanding of these recruitment efforts in general and those related to the recruitment of URM students is therefore of interest. Concerning who is engaged in recruitment efforts, the responses showed that the majority of programs did not have a designated recruiter. When recruiters were designated, they were in the majority of cases dental hygienists or staff members. In addition, faculty members, program administrators, and students participated in the recruitment process. Given the low percentages of faculty members from URM groups, ${ }^{14,15}$ it is unlikely to have black or Hispanic recruitment personnel involved in these processes.

When questions focused on how the programs recruit students, the data showed that $91 \%$ of the responding programs had written materials and 
Table 6. Correlations between dental hygiene program directors' priority, importance, and satisfaction ratings and program- and recruitment-related characteristics

\begin{tabular}{|c|c|c|c|c|c|c|}
\hline & $\begin{array}{l}\text { Number } \\
\text { of } \\
\text { Applicants }\end{array}$ & $\begin{array}{l}\text { Number of } \\
\text { Graduates in } \\
\text { Average Year }\end{array}$ & $\begin{array}{l}\text { Percentage } \\
\text { of URM } \\
\text { Graduates }\end{array}$ & $\begin{array}{l}\text { Program } \\
\text { Length }\end{array}$ & $\begin{array}{c}\text { Written } \\
\text { Material for } \\
\text { URM Students }\end{array}$ & $\begin{array}{c}\text { Special Event } \\
\text { for URM } \\
\text { Students }^{+}\end{array}$ \\
\hline \multicolumn{7}{|l|}{ Priorities } \\
\hline $\mathrm{ACT}$ & $0.41 * *$ & -0.01 & 0.11 & -0.11 & 0.06 & $-0.38^{*}$ \\
\hline GPA & 0.19 & 0.10 & 0.01 & 0.29 & 0.02 & -0.19 \\
\hline Family & 0.12 & 0.15 & -0.04 & -0.04 & -0.13 & -0.22 \\
\hline Professional & -0.06 & -0.09 & 0.05 & -0.20 & 0.05 & -0.11 \\
\hline Diversity index ${ }^{\ddagger}$ & -0.20 & -0.05 & -0.00 & 0.09 & $0.34^{*}$ & 0.04 \\
\hline \multicolumn{7}{|l|}{ Importance } \\
\hline ACT & $0.29 *$ & -0.11 & 0.03 & -0.19 & -0.01 & $-0.34^{*}$ \\
\hline GPA & $0.27^{*}$ & 0.16 & 0.08 & 0.13 & -0.10 & -0.05 \\
\hline Family & 0.07 & 0.13 & -0.06 & -0.09 & -0.14 & -0.17 \\
\hline Professional & -0.06 & -0.04 & 0.08 & -0.17 & 0.10 & 0.01 \\
\hline Diversity index ${ }^{\ddagger}$ & -0.24 & -0.05 & 0.03 & -0.13 & $0.39 * *$ & -0.00 \\
\hline \multicolumn{7}{|l|}{ Satisfaction } \\
\hline ACT & 0.04 & -0.10 & 0.13 & 0.05 & -0.12 & -0.05 \\
\hline GPA & 0.07 & -0.11 & 0.02 & 0.08 & 0.00 & 0.12 \\
\hline Family & -0.24 & -0.18 & 0.14 & 0.08 & -0.14 & -0.03 \\
\hline Professional & -0.20 & -0.19 & 0.14 & -0.03 & 0.05 & 0.13 \\
\hline Diversity index ${ }^{\ddagger}$ & -0.18 & -0.15 & $0.34^{*}$ & -0.13 & -0.03 & 0.23 \\
\hline $\begin{array}{l}\text { Note: Response opti } \\
{ }^{+} \text {Response options w } \\
{ }^{*} \text { The average diversit } \\
\text { *Statistically significa }\end{array}$ & $\begin{array}{l}\text { ons ranged } \mathrm{fr} \\
\text { ere } 0=\text { no anc } \\
y \text {-related ind } \\
\text { int at } p<0.05\end{array}$ & $\begin{array}{l}\text { at all to } 5=v \\
\text { computed by } \\
\text { cally signific }\end{array}$ & $\begin{array}{l}\text { ch. } \\
\text { ing the resp } \\
<0.01\end{array}$ & the divers & ed questions. & \\
\hline
\end{tabular}

websites. However, only one in five had written materials that focused specifically on recruiting URM students. Given that these efforts mainly consisted of including pictures of URM students in the written materials, it seems unlikely that these materials were specifically focused on students from URM groups. If the text of the written materials had described the need for URM dental hygienists to provide care for underserved groups, such information might have motivated students to consider careers in dental hygiene. While $77 \%$ of the responding programs participated in recruitment events on their campuses, 29 programs engaged in high school visits, and 26 in other organized outreach events, only seven programs had specific outreach events for students from URM groups.

Despite this dire situation concerning the low numbers of URM students in dental hygiene programs, only a minority of the program directors considered recruiting students from diverse backgrounds (19\%) and from URM groups (17\%) a priority. This finding might be related to the fact that while the CODA standards for dental education programs require that the schools make efforts to have a diverse student body, staff, and faculty, ${ }^{20}$ we could not find any similar requirement in the CODA standards for dental hygiene programs. ${ }^{21}$ Placing low importance on such efforts might explain the respondents' relatively high satisfaction ratings with their efforts-despite the obvious lack of substantial numbers of students from these groups in the programs. These findings of the low priority given to creating a diverse educational setting and being satisfied with not having a diverse student body deserve attention. They provide a basis to argue for increased faculty and administrator development efforts to ensure that all program administrators become aware of the fact that providers from URM groups are more likely to provide care for underserved populations $^{2-11}$ and thus might positively affect the degree to which URM patients are underserved. In addition, such efforts should focus on increasing an understanding of the importance of educating culturally sensitive providers, which is supported by a diverse educational setting. ${ }^{7,12,23}$

While $56 \%$ of the program directors in our study reported that they had sufficient funds for recruiting, several respondents indicated that their biggest challenges in general and when recruiting students from URM groups were a lack of time and the costs involved. This finding raises the question 
of how recruitment efforts could focus on including practicing dental hygienists in recruitment efforts. ${ }^{24,25}$ Involving alumni of dental hygiene programs could potentially be an effective way to increase the number of applicants in general and the number of URM applicants specifically. This suggestion is also supported by the finding that word of mouth and oneon-one recruitment efforts were said to be the most effective recruitment practices for these programs. Considering other practices for the recruitment of URM students such as informing students earlierfor example in high school ${ }^{25,26}$ - and engaging high school counselors more actively ${ }^{25}$ should definitely happen as well. In addition, the responses of URM dental hygiene students about their decisions to enroll in these programs reported in Sandino and Rowe's study could be quite helpful in developing specific recruitment approaches. ${ }^{16}$

Finally, educating dental hygiene administrators and admissions committee members about holistic approaches to recruiting students might also be crucial to bring about change. ${ }^{19}$ The data in our study showed that the more program directors placed a priority on ACT scores and considered them as important, the less they engaged in special events for URM students.

This study had two major limitations. First, the response rate was rather low. This might be another indicator that the program directors who received individualized emails did not consider the topic of recruiting URM students important enough to respond to the survey. However, one might argue that if more programs had responded, the findings might have been even more discouraging. Distributing a survey at the annual meeting of dental hygiene program directors might be one way to achieve a higher response rate. Second, collecting only survey data might not provide an objective picture of actual recruitment efforts. Collecting more objective data such as written materials from programs or information from their websites and content-analyzing that information could provide additional insights into the recruitment efforts. Also, some programs may be able to recruit more URM students because of location or tuition and fees, and our study may not have captured those sorts of distinctions.

\section{Conclusion}

The numbers of U.S. dental hygiene students from URM groups do not match the percentages of individuals from these population groups in the United States. However, this study found that recruiting dental hygiene students from diverse backgrounds and from URM groups was not a priority for most of the responding dental hygiene program directors. On the contrary, they were on average satisfied with their efforts. Efforts to recruit students from URM groups were not widely embraced and could definitely be improved.

\section{Acknowledgments}

We want to thank the dental hygiene program directors who responded to this survey.

\section{REFERENCES}

1. Oral health in America: a report of the surgeon general. 2000. At: http://profiles.nlm.nih.gov/ps/access/NNBBJT pdf. Accessed 1 Apr. 2015.

2. Lacy ES, McCann AL, Miller BH, et al. Achieving student diversity in dental schools: a model that works. J Dent Educ 2012;76(5):523-33.

3. Smith SG, Nsiah-Kumi PA, Jones PR, Pamies RJ. Pipeline programs in the health professions, part 1: preserving diversity and reducing health disparities. J Natl Med Assoc 2009;101(9):836-47.

4. Onik E. Missing persons: African Americans in dental hygiene. J Dent Hyg 2009;83(2):62-9.

5. Sullivan Commission. Missing persons: minorities in the health professions. 2004. At: https://depts.washington. edu/ccph/pdf_files/Sullivan_Report_ES.pdf. Accessed 1 Apr. 2015.

6. Rosella JD, Regan-Kubinski MJ, Albrecht SA. The need for multicultural diversity among health professionals. Nurs Health Care 1994;15:242-6.

7. DeVore LR. Participation of minorities in U.S. dental education. J Dent Educ 1995;59(6):631-9.

8. Field MJ, ed. Dental education at the crossroads: challenges and change. An Institute of Medicine study. Washington, DC: National Academy Press, 1995.

9. Reed MJ. The IOM study and minority issues. J Dent Educ 1996;60(4):441-5.

10. Cohen JJ. Finishing the bridge to diversity. Acad Med 1997;72:103-9.

11. Tedesco LA. Post-affirmative action Supreme Court decision: new challenges for academic institutions. J Dent Educ 2005;69(11):1212-21.

12. Dhir I, Tisk MN, Tira DE, Holt LA. Ethnic and racial minority students in U.S. entry-level dental hygiene programs: a national survey. J Dent Hyg 2002;76(3):193-201.

13. Woolfolk MW, Price SS. Dental education: evolving student trends. J Dent Educ 2012;76(1):51-64.

14. American Dental Association. 2010-11 survey of allied dental education. Chicago: American Dental Association, 2012.

15. Nunn PJ, Gadbury-Amyot CC, Battrell A. The current status of allied dental faculty: a survey report. J Dent Educ 2004;68(3):329-44. 
16. Sandino AH, Rowe DJ. Students from underrepresented racial and ethnic groups entering the dental hygiene profession. J Dent Educ 2014;78(3):465-72.

17. Arnett MR. Increasing student diversity and cultural competence as part of Loma Linda University School of Dentistry's service mission. J Dent Educ 2012;76(6): 721-7.

18. McClain MA, Jones FR, McClain CR, Curd FM. Increasing dental student diversity through the UNLV dental prospects program. J Dent Educ 2013;77(5):548-53.

19. Price SS, Mills DG. Effective admissions practices to achieve greater student diversity in dental schools. J Dent Educ 2010;74(10 Suppl):S87-97.

20. Commission on Dental Accreditation. Accreditation standards for dental education programs. 2013. At: www.ada. org/ /media/CODA/Files/predoc_2013.ashx. Accessed 1 Apr. 2015.
21. Commission on Dental Accreditation. Accreditation standards for dental hygiene programs. 2012. At: www.ada. org/ /media/CODA/Files/dh.ashx. Accessed 1 Apr. 2015.

22. Howard CJ. International student enrollment in U.S. dental hygiene schools. J Dent Hyg 1997;71:112-6.

23. Hill HC. The importance of minority perspective in the classroom. Chron Higher Educ 1997;44:A60.

24. Cohen JJ. Project 3000 by 2000 and health care reform. Acad Med 1994;69(9):728.

25. Baldwin A, Agho AO. Student recruitment in allied health educational programs: the importance of initial source of contact. J Allied Health 2003;32(2):65-70.

26. Inglehart MR, Stefanac SJ, Johnson KP, et al. Recruiting URM high school students into dental professions and educating dental students about academic careers. J Dent Educ 2014;78(3):423-36. 